\title{
Impact of Various Vegetation Types on Mobile Laser Scanning Elevation Accuracy
}

\author{
Natalja Liba, Kaupo Kokamägi, Ina Järve, Estonian University of Life Sciences
}

\begin{abstract}
Geodesy is currently experiencing a rapid and very diverse development of surveying technologies. Therefore it is important to evaluate the suitability of one or another technology in different situations for different tasks. This is especially needed for geodesy companies to make the right investment decisions. One of the innovative measurement technologies is mobile laser scanning, a rapidly evolving method of collecting survey data. It is mainly used for surveying objects such as streets, roads, railways and rivers. The results of mobile laser scanning can be used in everyday geodesy as well as for making three-dimensional models. As the development of other technologies makes it possible to process large amounts of mobile laser scanning data, this measuring method will soon become increasingly more attractive in Estonia. The paper analyses the technology of mobile laser scanning in one specific situation pointing out the dependence of elevation accuracy on the nature of the vegetation. It also analyses the amount of accuracy of mobile laser scanning technology that it is possible to increase by using cross-section profiles. For accuracy assessment, the mobile laser scanning elevation data and control points measured with GNSS device were compared. The study found that the elevation accuracy of mobile laser scanning depends substantially on the density and height of vegetation. Drawing ground profiles increases the accuracy of the final result. The result of RMSE of mobile laser scanning elevation data was 0.70 meters, the result of the RMSE of mobile laser scanning elevation data using drawing ground profile was 0.53 meters. It can be concluded that the most reasonable time for conducting mobile laser scanning would be during the season when vegetation is sparsest.
\end{abstract}

Keywords: laser scanning; mobile laser scanning; accuracy of elevation data.

\section{Introduction}

Laser scanning is a survey method that collects $X$, $\mathrm{Y}$ and $\mathrm{Z}$ coordinates from surrounding environment for representing spatial image of a surveyed object. For that specific technology is used. The result from scanning is a point cloud that after processing is combined into the model and bound into the coordinate system. [2] It is possible to make 2D drawings and 3D models, fix objects from environment, make control measurements and so on from point clouds. [8]

Laser scanning is divided into the terrestrial and aerial laser scanning. Terrestrial laser scanning can

also be divided into the static and mobile laser scanning. In the static mode, the scanning is carried out in one fixed stabile position on the ground level: on a tripod. Mobile laser scanning is performed on a moving vehicle (a car, a train or a boat). Often, laser scanning systems used on water are treated as a separate scanning thread called a Boat-Based Mobile Mapping System (BoMMS) [5]. Aerial laser scanning is carried out by aircraft.

Figure 1 shows different ways of scanning.

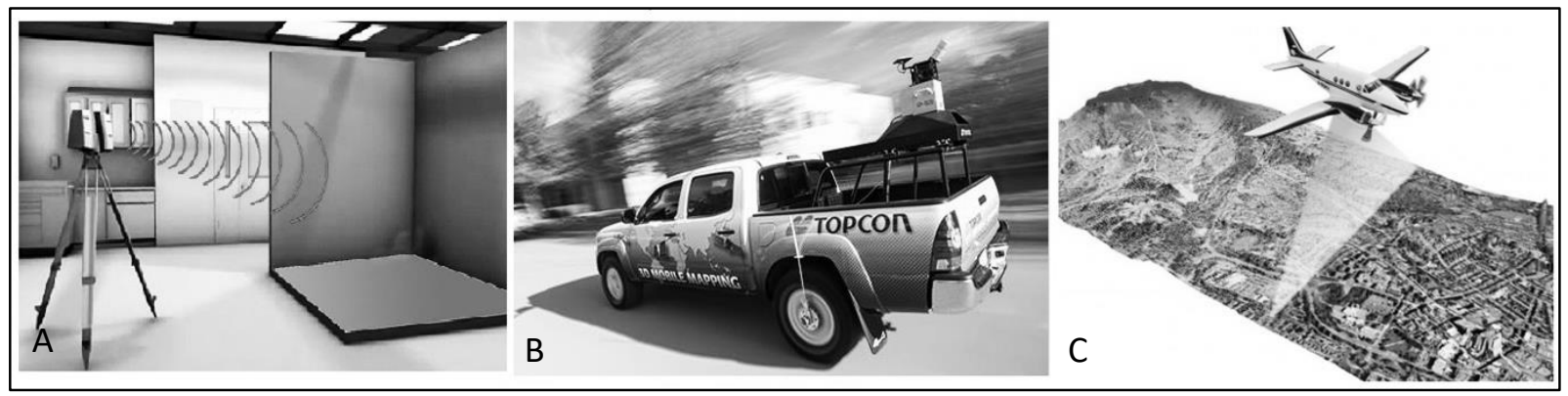

Fig, 1. Methods of laser scanning: A) static laser scanning in room on a tripod [16]; B) mobile laser scanning outside from the car [17]; C) aerial laser scanning from an aircraft [15]

Laser scanning was invented in the beginning of the 1960s, but the technology then did not allow to use devices for mapping. In the middle of the 1990s, the technology of direct positioning and the overall development of computer technology enabled to use laser and scanning systems in topographic mapping. Since then, the laser scanner has been used in geodesy and engineering sciences. [11]

One of the innovative measurement technologies is mobile laser scanning. It is a rapidly evolving way 
of collecting survey data. The first mobile laser scanning system began to spread abroad in the late 1990 s, and since then the scope and the supporting hardware of the laser has increased [7]. Therefore, the use of mobile laser scanning systems has become increasingly attractive and more common for foreign geodetic companies.

Mobile laser scanning is a new direction for geodetic companies in Estonia also. At the moment, only few companies have their own mobile laser scanners, mostly hardware is borrowed from abroad through different projects [13]. Before using the hardware, it is necessary to investigate its accuracy and effectiveness. Several companies cooperate with the Estonian universities, including the Estonian University of Life Sciences (a Chair of Geomatics) where several graduation theses have been written in this field.

Researchers at the Estonian University of Life Sciences with students studied the accuracy of mobile laser scanning elevation data in forests and open areas. From the results it can be concluded that highlevel objects beside the road areas affect the elevation data reached by the mobile laser scanning system. In geodetic works, requiring greater accuracy, additional methods such as denser placement of positioning marks, should be used. [1].

The above described method was investigated in the USA, California, where an experiment was conducted to find out what is the indicative placement for the marks on the road and what is the accuracy of the point cloud according to the placement. The results showed that the standard deviation remains constant after 1,200 meters between marks. It appeared from the 24-hour experiment that the vertical error decreased $51 \%$ and more using ground control targets, even at very large target spacing. [10]

In 2016, mobile laser scanning in one of the car parks of Tallinn University of Technology was conducted at various speeds. The point clouds of mobile laser scanning and static terrestrial laser scanning were compared. It turned out that differences in absolute values did not exceed $15 \mathrm{~cm}$ in most cases. [4]

In current research, mobile laser scanning technology is analysed, pointing out the dependence of elevation accuracy on the nature of the vegetation and distance of the measurement. It is also analysed how much it is possible to increase accuracy of mobile laser scanning technology by using crosssection profiles.

\section{Materials and methods}

The methodology of the research can be divided as follows:

- Collecting laser scanning data;

- Data processing and additional surveys outside;

- Elevation accuracy assessment by control points;

- Analysis and conclusions.

\section{Collecting laser scanning data}

Mobile laser scanning data used in research were collected in the summer of 2015 on the route TallinnTartu (E263) in the section of Põltsamaa-Kärevere. The project was carried out according to the order of Estonian Road Administration and accomplished by an Estonian surveying company OÜ REIB.

For the preparation, the pavement markings, used as control points, were measured with a GNSS device Trimble R8. Measurements were done early in the morning.

The scanning was carried out on June 30, 2015. Collecting scanning data lasted about two hours and about $40 \mathrm{~km}$ of road was scanned in that time. Scanning was performed by the continuous measurement method. In this case, the vehicle moved along the trajectory without stopping.

As the vehicle moves along the trajectory, a threedimensional point cloud draws out from the profiles (Figure 2).

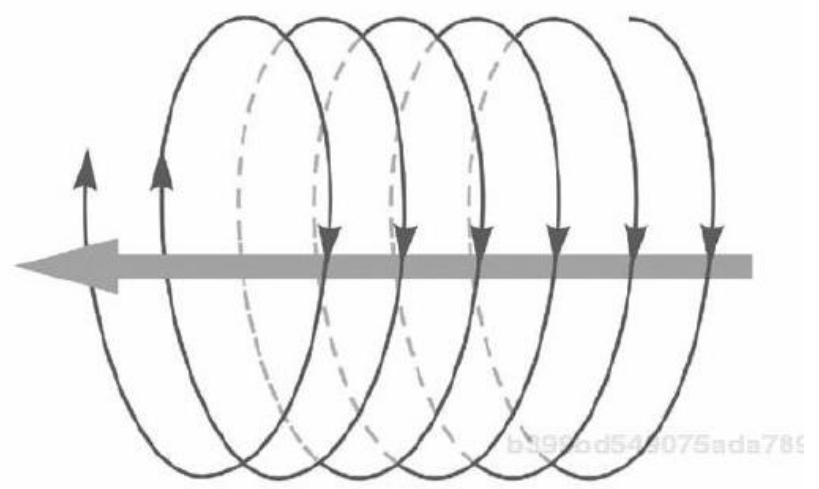

Fig. 2. Mobile laser scanning made by the continuous measurement method: the point cloud is formed by the profiles perpendicular to the direction of travel [14] 
The scanning density is directly related to the speed of the vehicle carrying the laser scanner. At higher speed, the point density is lower. To initialize and calibrate the IMU (Inertial Measurement Unit) and GNSS devices for mobile laser scanning, the vehicle moved on the road back and forth at a speed of approximately $80 \mathrm{~km} / \mathrm{h}$. At that speed the point cloud density, 5 meters from scanner, was 430 points per square meter (Table 1). Mobile laser scanner system StreetMapper 360 was used for this research. The system has two Riegl VQ250 laser scanners. During the scanning two Ashtech XII GNSS receivers were set up on geodetic reference network points in each end of the road section and data were collected during the whole scanning.

TABLE 1

Average point density of VQ250 laser scanners used for scanning the Põltsamaa-Kärevere section (StreetMapper 360 Specifications)

\begin{tabular}{|l|c|c|c|c|c|}
\hline & \multicolumn{5}{|c|}{$\begin{array}{c}\text { Average point density per 1 scanner (points } \\
\text { per square meter, 5 meters from scanner) }\end{array}$} \\
\hline Speed $(\mathrm{km} / \mathrm{h})$ & 25 & 30 & 60 & $\mathbf{8 0}$ & 100 \\
\hline Point density $\left(\mathrm{pt} / \mathrm{m}^{2}\right)$ & 1375 & 860 & 573 & $\mathbf{4 3 0}$ & 344 \\
\hline
\end{tabular}

Each measurement produces points in a new coordinate system. For producing a point cloud in general coordinate system, the mobile scanner is equipped with GNSS receiver and IMU device (Figure 3). In addition, the watches for all sensors must be exactly synchronized. [14]

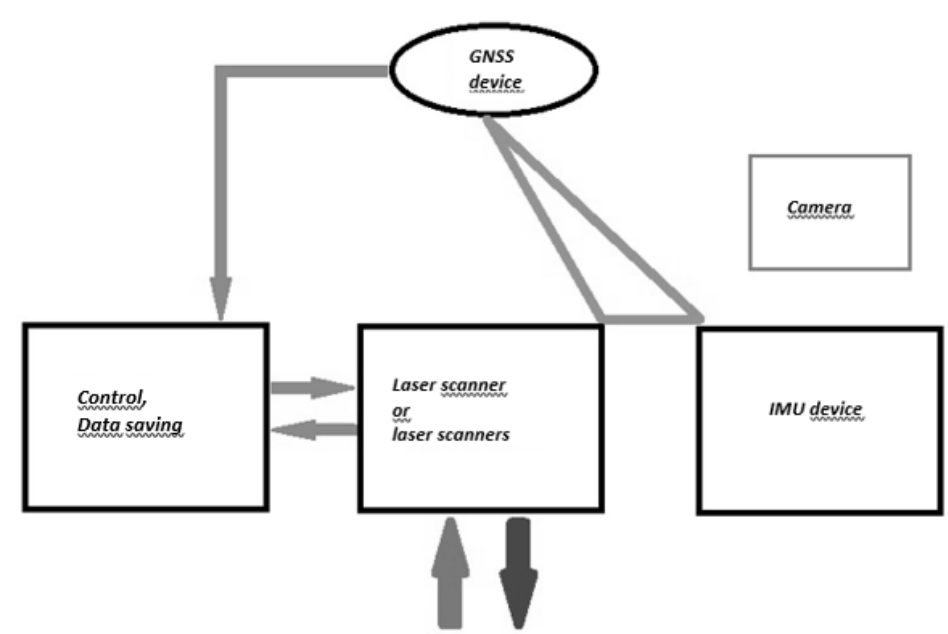

Fig. 3. Mobile and aerial laser scanning system parts on board [14]

Data processing and additional surveys

Data processing and additional surveys took place after receiving scanning data. An important part here is the software which is used to merging overlapping point clouds, connecting point cloud in global coordinate system and removing deviated points from the point cloud [6]. Data processing is done by software AutoCAD LT 2014, AutoCAD Civil 3D 2015 and by Autodesk Recap 2015.
During data processing, the point clouds were classified and corrected. Control points coordinates measured previously and GNSS data were used for that. The point cloud was divided into smaller sections to make the further processing smoother. Then ground profiles were drawn after every 25 meters. This was done for making the ground elevation model (Figure 4). 


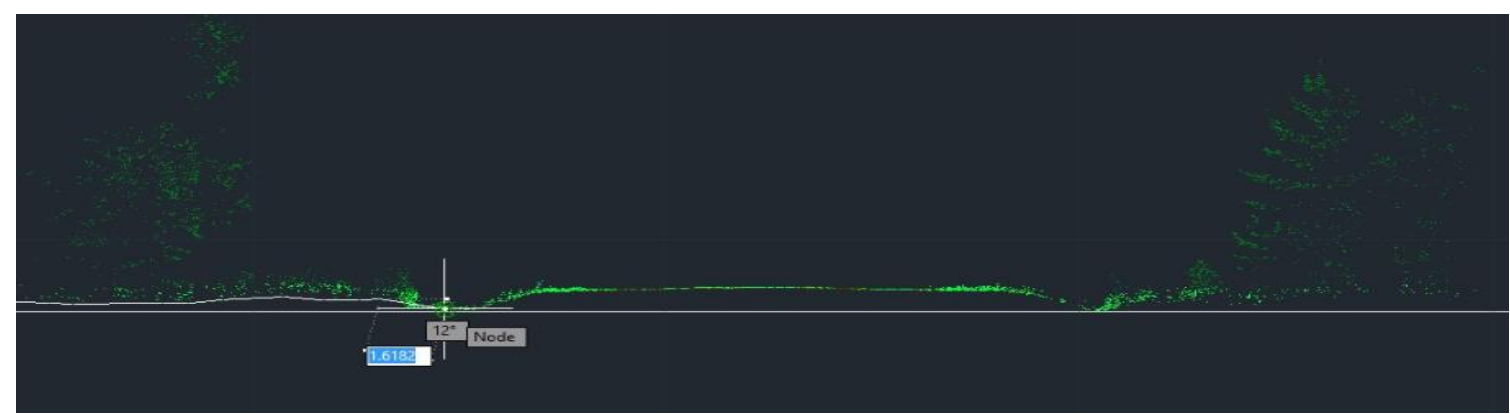

Fig. 4. Drawing ground cross-section profile with AutoCAD

The places without enough information in the point cloud (like road crossing ditches and rivers) were surveyed with total station and GNS devices during additional surveys.

\section{Accuracy assessment of elevation data}

An extra road section Kärevere-Põltsamaa with adjacent areas was measured for the research. Three different vegetation polygons formed from the section. In order to study the dependence of elevation accuracy on the nature of vegetation and on the distance of the survey, the mobile laser scanning elevation data were compared to elevation data of GNSS control points. Also, the accuracy of mobile laser scanning elevation data was compared to the accuracy of ground profile elevation data in order to analyse the level of accuracy of mobile laser scanning technology that it is possible to increase by using cross-section profiles obtained from the point cloud.

Only classified, corrected and block-sectioned point clouds were used in this research.

The characterization of the three chosen polygons:

- Polygon I: a field vegetated with 1 meter high crop. 73 checkpoints were measured (Figure 5);

- Polygon II: a pasture with low and sparse vegetation. 50 checkpoints were measured (Figure 6);

- Polygon III: contained a bushy ditch and a field behind it. 97 checkpoints were measured (Figure 7).

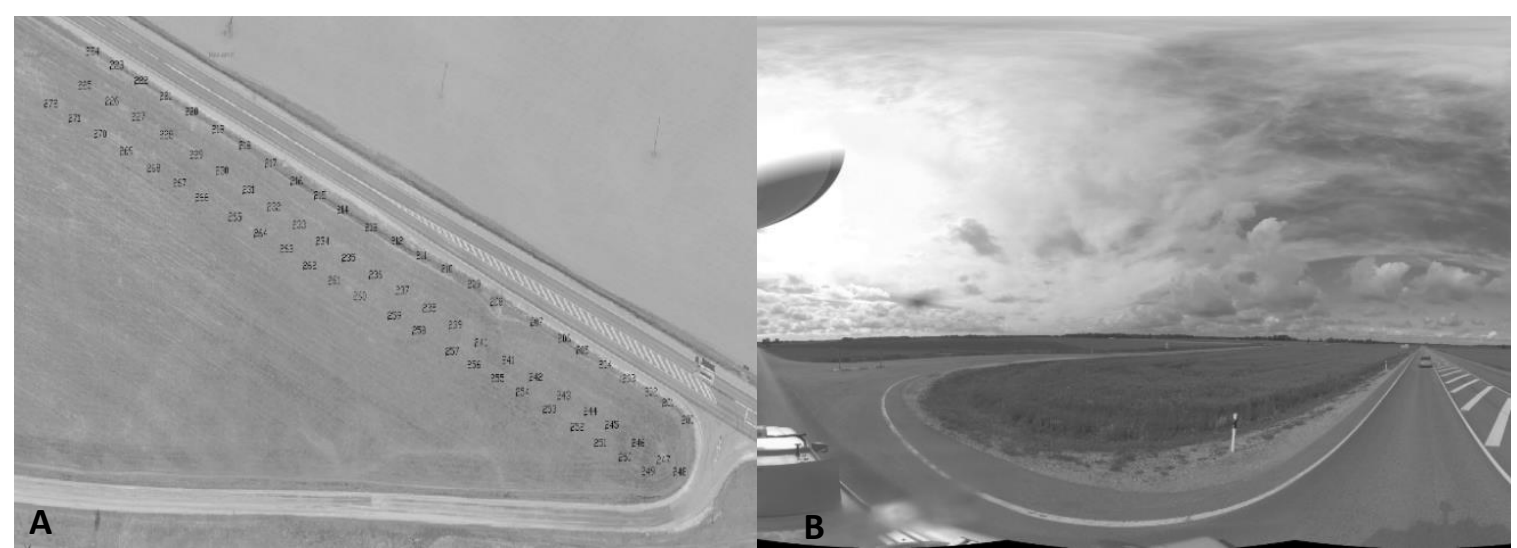

Fig. 5. Polygon I: A) the layout of checkpoints measured with a GNSS device, B) photographed from the mobile scanning system during the scanning 


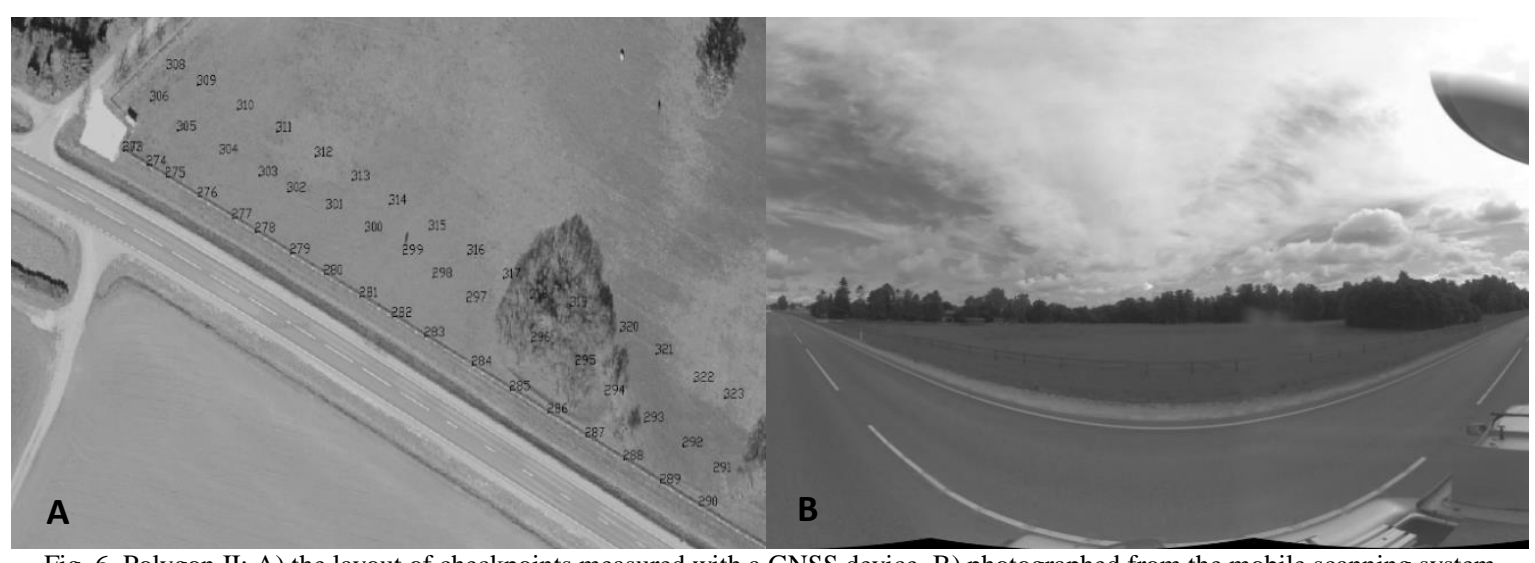

Fig. 6. Polygon II: A) the layout of checkpoints measured with a GNSS device, B) photographed from the mobile scanning system during the scanning

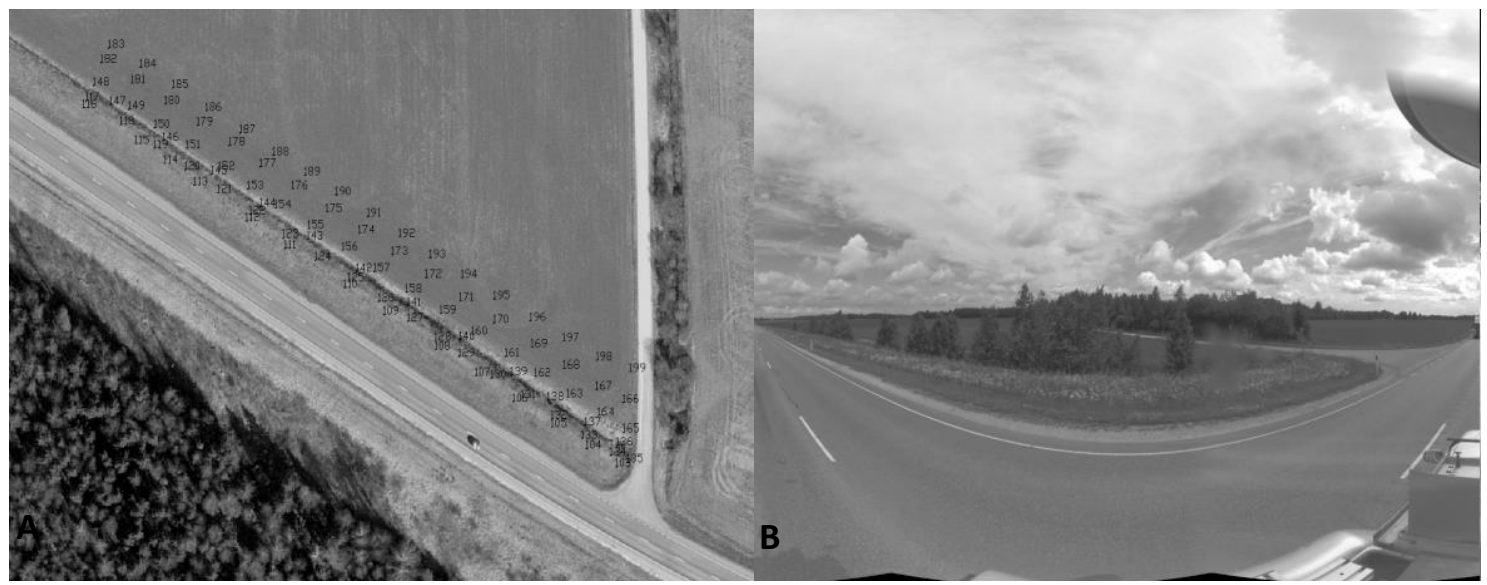

Fig. 7. Polygon III: A) the layout of checkpoints measured with a GNSS device, B) photographed from the mobile scanning system during the scanning

The survey with GNSS device Trimble R4-3 was conducted in each polygon after mobile laser scanning, and the results of the survey were considered accurate for the research. The points were measured in rows parallel to route E263, each row further from the road than the last. The first row was 3 to 5 meters from the edge of asphalt and the rows were 5 to 10 meters apart from each other. In Polygons I and II there were 3 rows and in Polygon III there were 6 rows, because there were additional rows measured in the bottom of the ditch and on the top of the banks in Polygon III. Two closest points were selected for each control point from the mobile laser scanning data, and the average elevation value was calculated.

59 ground cross-profiles in the control point's locations were drawn from the laser scanning data. The profiles were drawn perpendicular to the road at the distance about 25 meters from each other. Two breakpoints for 30 profiles and one breakpoint for 29 profiles closest to the control point were used. The points used for the comparison of elevation data were located in each polygon in several rows. The elevation accuracy of the different lines was also compared.

\section{Data analysis and conclusions}

The measuring took place in three polygons. The RMSE (Root Mean Square Error) of elevation data was computed for each polygon in both data processing methods: laser scanning and ground profile based on mobile laser scanning. Firstly, the results of the RMSE of every polygon measured in different methods were compared. Secondly, the results of the mean RMSE of all polygons measured in a different method were compared.

Gaussian RMSE formula was used for assessment of the accuracy of elevation [9].

The results of the RMSE of each polygon in mobile laser scanning were as follows:

- Polygon I (a field vegetated with 1 metre high crop) - $0.98 \mathrm{~m}$;

- Polygon II (a pasture with low and sparse vegetation) $-0.23 \mathrm{~m}$;

- Polygon II (with high vegetation contained a bushy ditch and a field behind it) $-0.61 \mathrm{~m}$.

The results of the RMSE of ground profile elevation data in different polygons were: $0.69,0.27$ and 0.54 meters, respectively (Figure 8). 


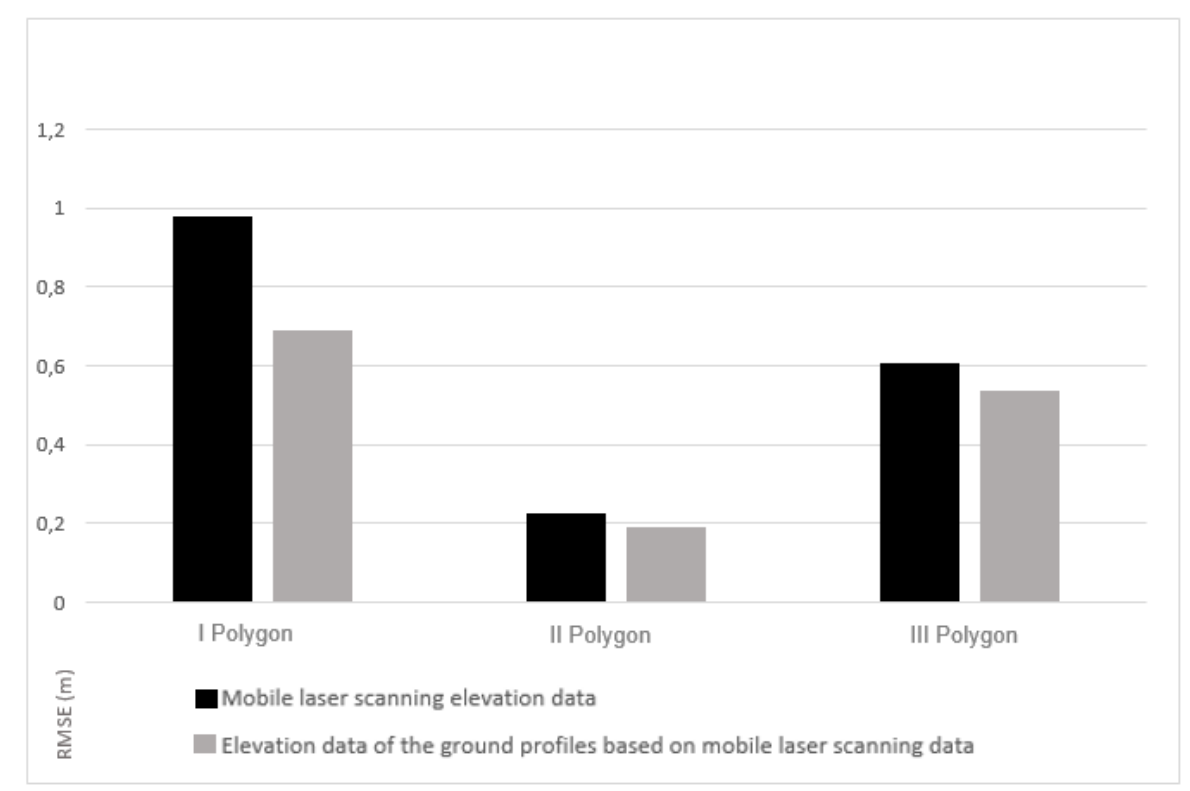

Fig. 8. Comparison of elevation data RMSE's using different measuring methods in Polygons I, II and III

The most accurate elevation data from all three polygons using different measurement method was obtained in Polygon II covered with low vegetation. Surprisingly, the most inaccurate data were in Polygon I covered with crop. In this case the result of the RMSE from mobile laser scanning data was 0.98 $\mathrm{m}$, which was also the approximate height of the crop. As it was very densely populated vegetation, the upper part of the vegetation was probably identified automatically as the ground, which caused the mistake.
As expected, cross-profiles affected mobile laser scanning data to be more accurate. This is possible because the places that are unidentified by laser scanning may be identified by drawing cross-sections (for example, areas behind thick bushes).

The result of the RMSE of the elevation data of three polygons put together was 0.70 meters for mobile laser scanning and 0.53 meters for profiles based on mobile laser scanning. The comparison of the mean accuracy of three sections put together is shown in Figure 9.

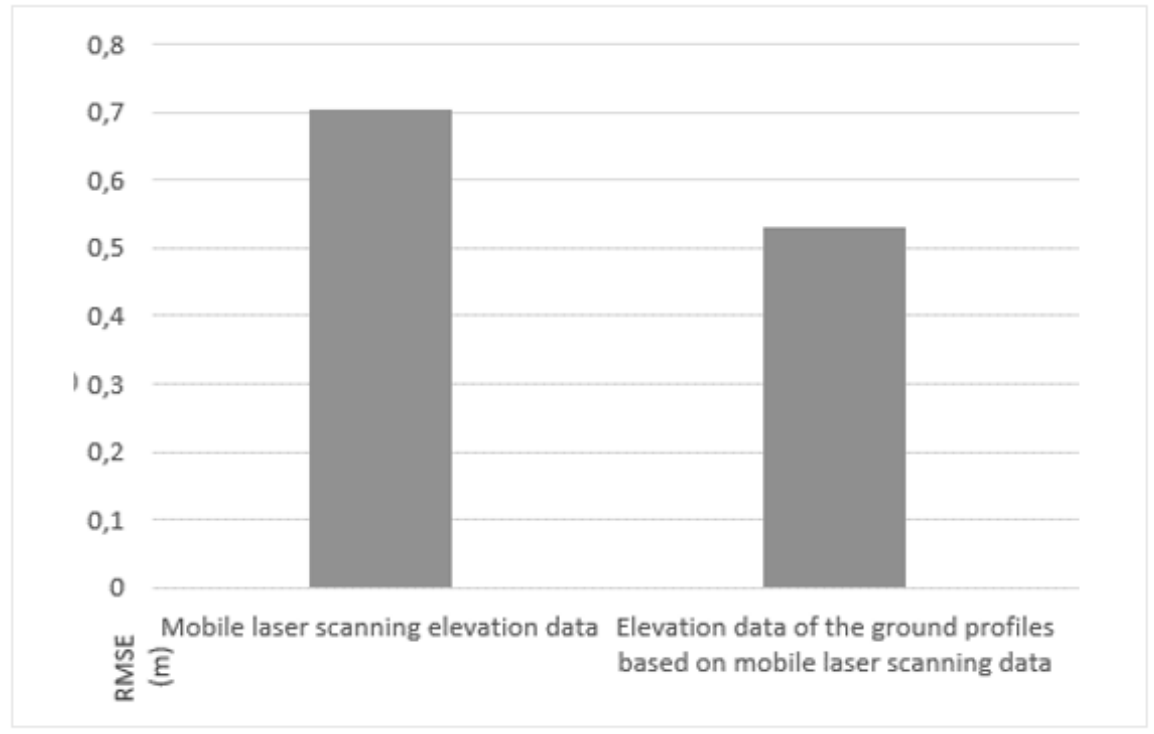

Fig. 9. Comparison of mean elevation data RMSE's of all the polygons using different measuring methods

Results of the research show that the accuracy of mobile laser scanning elevation data depends substantially on the density of vegetation in a scanned area. It can be said that scanning gives more accurate results at the time when there is less vegetation, in early spring or in late autumn. Also, drawing the cross profiles increases the elevation accuracy of mobile laser scanning data. It was also found that the 
further from the mobile scanner the point is, the larger

RMSE results of elevation data become.

\section{References}

1. Annok, G. Mobiilse laserskaneerimise kõrguslik täpsus erineva taevalaotuse korral, 2017. (Bachelor's thesis). Estonian University of Life Sciences, Institute of forestry and Rural Building. Tartu. $41 \mathrm{p}$.

2. Barber, D., Mills, J. 3D Laser Scanning for Heritage: Advice and guidance to users on laser scanning in archaeology and architecture [online]. United Kingdom: English Heritage, 2011 (cited 16.08.2016).

3. Joala, V. Laserskaneerimine - suure detailsusega 3D-mõõtmine. - TeeLeht. 2006. No 2, p. 21-23.

4. Julge, K., Ellmann, A., Vajakas, T., Kolka, R. Initial Tests and Accuracy assessment of a Compact Mobile Laser Scanning System [online], 2016. Prague, Czech Republic. ISPRS, volume XLI-BI. https://www.int-arch-photogramm-remote-sens-spatial-infsci.net/XLI-B1/633/2016/isprs-archives-XLI-B1-633-2016.pdf

5. Kukko, A., Kaartinen, H., Hyyppä, J., Chen Y. Multiplatform Mobile Laser Scanning: Usability and Performance - Sensors, 2012. No 12, p. 11712-11733.

6. Lee, S.Y., Majid, Z., Setan, H. 3D Data Acquisition for Indoor Assets Using Terrestrial Laser Scanning [online], 2013 (cited 12.08.2016). Turkey. 6 p. http://www.isprs-ann-photogramm-remote-sens-spatial-inf-sci.net/II-2-W1/221/2013/isprsannals-II-2-W1221-2013.pdf

7. Puttonen E., Lehtomaki M., Kaartinen H., Zhu L., Kukko A., Jaakkola A. Improved Sampling for Terrestrial and Mobile Laser Scanner Point Cloud Data - Remote Sensing, 2013. No 5, p. 1754-1773.

8. Pärtna, J. Tänapäevastest mõõdistustehnoloogiatest - TeeLeht. 2016. № 84, p 37-39.

9. Randjärv, J. Geodeesia I, 1997. Tartu. 399 p.

10. Ravani B., Yen K., Lasky T.A., Donecker S., Jian Z. Application of Mobile Laser Scanning for Lean and Rapid Highway Matinenance and Construction [online], 2015 (cited 23.11.2016). United States of America. 65 p. http://ahmct.ucdavis.edu/pdf/UCDARR-15-08-28-01.pdf

11. Shan, J., Toth, C. K. Topographic laser ranging and scanning: principles and processing, 2009. United States of America: CRC Press. $590 \mathrm{p}$

12. Staiger, R. Terrestrial Laser Scanning Technology, Systems and Applications, 2003. Germany. 10 p.

13. Toompuu, B., Alanurm, K. Laserskaneerimise andmete ja tehnoloogia kasutamine Eestis, 2013. (Bachelor's thesis). Estonian University of Life Sciences, Institute of forestry and Rural Building. Tartu. $85 \mathrm{p}$.

14. Vosselman G., Maas H. G. Airbone and terrestrial laser scanning, 2010. Whittles Publishing. 318 p.

15. Informed Infrastructure. http://informedinfrastructure.com/12620/reality-computing-for-civil-infrastructure (cited 30.10.2017)

16. Ingeniería y Arquitectura Sinluz. http://www.sinluz.com/servicios/57-servicios/topografia/escaneado-laser-3d-para-arquitectura (cited 30.10.2017)

17. Topcon Positioning Systems, Inc. https://www.topconpositioning.com/utilities (cited 30.10.2017) 